\title{
Systemic cholesterol embolism
}

\author{
Hurtarte Sandoval AR ${ }^{1 *}$, Rodelo Haad $\mathrm{C}^{*}$, Sánchez Sánchez $\mathrm{R}^{2}$, Gómez Carrasco J ${ }^{1}$, Ortega Salas R ${ }^{2}$ and Aljama García P1 \\ ${ }^{1}$ Department of Nephrology, Reina Sofia Hospital, Cordoba, Spain \\ ${ }^{2}$ Department of Pathology, Reina Sofia Hospital, Cordoba, Spain
}

\begin{abstract}
Atheroembolism is a systemic disease with variable clinical manifestations due to embolization of cholesterol crystals from atherosclerotic plaques in large arteries. It is usually triggered by invasive vascular procedures or after the onset of anticoagulants such as heparin, low- molecular weight heparins, warfarin and fibrinolytic therapy. Clinical manifestations are variable; from skin lesions, myalgias, weight loss and fever to abdominal and neurological symptoms. The diagnosis is determined by clinical signs, the presence of cardiovascular risk factors and the time interval from interventions. However, skin or kidney biopsy may be performed to support diagnosis. We report the case of a 77-year-old man admitted to the hospital due to confusional state and mottled purpuric lesions on the left foot. The patient had a personal history of coronary stenting one month before admission. Brain CT scan showed multiple and chronic lacunar infarctions. He developed a rapid decline in renal function, and hemodialysis was started. The diagnosis was possible by performing a skin biopsy. After three months on hemodialysis, our patient has recovered renal function and is doing well in our outpatient clinic.
\end{abstract}

\section{Background}

The cholesterol embolization syndrome (CES) is originate in the descending thoracic and abdominal aorta, and may cause acute kidney injury (AKI). The abdominal aorta and ileo-femoral arteries are the most common sources of atheroembolism and $80 \%$ of cases are due to invasive vascular procedures [1]. Atherosclerosis is essential for CES development [2]. Kidneys are the most frequently affected organs due to the proximity of the renal arteries to the abdominal aorta. Recovery of renal function after this condition occurred in about $25 \%$ of cases $[1,3,4]$.

A 77-year-old man with personal history of chronic hypertension, type 2 diabetes mellitus, chronic kidney disease (CKD) stage 3a-A1 (creatinine of $1.7 \mathrm{mg} / \mathrm{dl}$ and a glomerular filtration rate of $50 \mathrm{ml} / \mathrm{min}$ MDRD4) and coronary artery disease submitted to percutaneous revascularization one month before admission. The patient was admitted to the emergency room, with a five hours history of acute confusional state, irritability and an unremarkable neurological exam. Mottled purpuric skin lesions of the left foot were present on admission (Figure 1). Hollenhorst plaques were not present on visual exam. A simple blood test showed serum creatinine $3.4 \mathrm{mg} / \mathrm{dl}$, and GFR of $18 \mathrm{~mL} / \mathrm{min}$ (MDRD4), urea nitrogen $112 \mathrm{mg} / \mathrm{dl}, \mathrm{K}: 4.9 \mathrm{mEq} / \mathrm{l}$, blood peripheral eosinophilia and normal urine sediment analysis were also present. Abdominal ultrasound revealed normal kidney size and an appropriate parenchymal thickness. A brain CT scan showed left thalamic lacunar infarcts (Figure 2). A DTPA- renogram (Tc99m. MAG3) showed moderate to severe attenuation of blood flow in both kidneys. Because of the oscillation of confusional state, a cerebral MRI was performed showing multiple lacunar infarcts in pons and subcortical white matter of both cerebral hemispheres, only one of them on the left posterior frontal location of recent chronology (Figure 3).

\section{Discussion}

CES is produced by rupture of the atherosclerotic plaques that lodge small caliber arteries [4]. The main sources of emboli are atheromatous plaques in major arteries such as the aorta. Spontaneous haemorrhage, treatment with anticoagulants or fibrinolytic therapy may precipitate atheroembolism [1]. Major risk factor for embolization includes older age than 60 years, diabetes, male sex, smoking, hypertension and hypercholesterolemia [5-7].

About $70 \%$ of cases are related to medical interventions $[8,9]$.

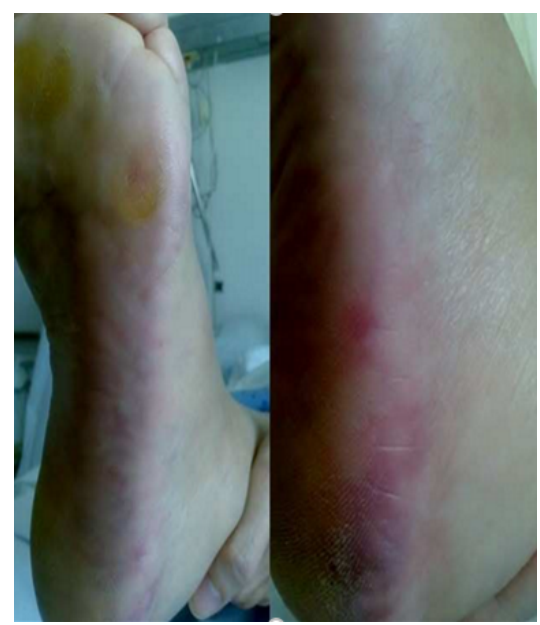

Figure 1. Red - purplish mottled lesions on right foot.

Correspondence to: Dr. Aldo René Hurtarte Sandoval, Servicio de Nefrología, Hospital Universitario Reina Sofía, Avda Menéndez Pidal s/n, Cordoba 14004, Spain, Tel: 34-957-010440; Fax 34-957-010307; E-mail: aldohurtarte12@hotmail.com

Cristian Rodelo Haad, Nephrology Department, Hospital Universitario "Reina Sofía”, Avda.Menéndez Pidal s/n, 14004 Córdoba, Spain, Tel: 34 686840152; E-mail: crisroha@yahoo.com

Received: December 15, 2015; Accepted: January 14, 2016; Published: January 18,2016 


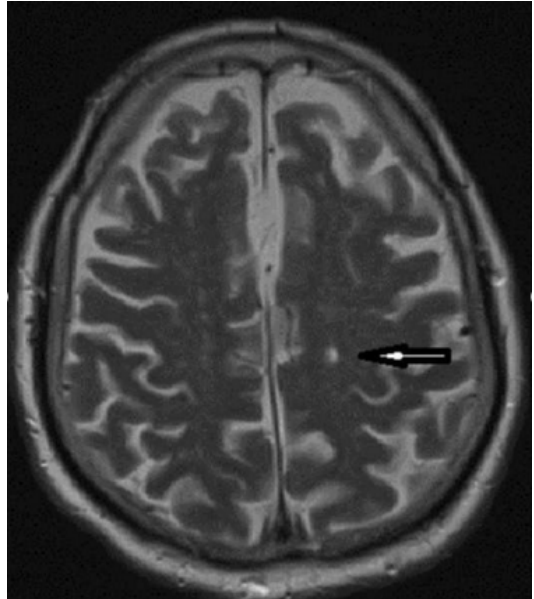

Figure 2. MRI shows multiple lacunar infarcts; one of them on the left posterior frontal location of recent chronology (black arrow).

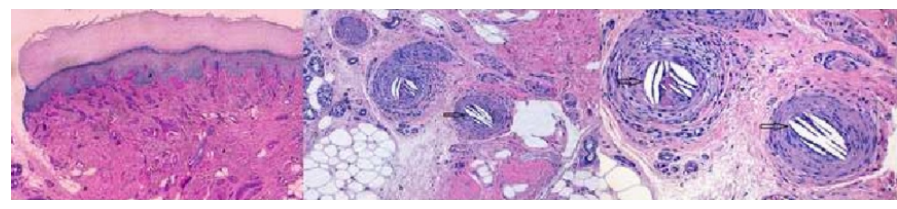

Figure 3. Skin biopsy shows biconvex cholesterol crystal clefts occluding emboli, besides, elongated needle-shaped clefts in small arteries, produced by cholesterol crystals (a, HE 40x; b, HE 100x; c, HE 200x).

Aortic interventions, such as angioplasty, are responsible for as many as $80 \%$ of cases $[5,10]$. Real incidence is unknown, but the prevalence may range from $1.8 \%$ to $77 \%$ depending on the series [1,7].

CES generates local inflammatory cell infiltration and activates innate immunity via the LRR, PYD and NACHT domains-containing protein (NLRP) 3 inflammasome. NLRP3 inflammasome senses the danger induced by various microorganisms or toxins. Recently, it has been described three different pathways of inflammasome activation: (i) disintegration with release of lysosomal contents by phagocytosed material, (ii) stimulation of reactive oxygen production at mitochondrial membranes and (iii) potassium filtration by membrane channels or ionophoric compounds. The NLRP3 inflammasome is a complex protein that activates caspase-1; these molecules induce an inflammatory response and recruitment of neutrophils and macrophages to the area of crystal formation. CES activates NLPR3 by the three pathways [11].

The classic triad of this disease includes recent precipitating event or subacute or acute kidney injury and skin findings, like livedo reticularis or blue toe syndrome.

Skin manifestations vary from $35 \%$ to $96 \%$. The highest percentages of patients with dermatologic manifestations have been observed in patients with renal involvement. Livedo reticularis is the most common dermatological manifestation. Neurological disorders occur in up to $23 \%$ of the patients with CES [1]. Transient ischaemic attack, stroke and mental confusion are common findings. Retinal emboli (Hollenhorst plaques), are present in up to $25 \%$ of the patients $[1,3]$.

AKI onset develops within one or two weeks after an invasive procedure [12]. Scolari et al. showed, on renal biopsy proven CES, progression to ESRD that require dialysis in approximately $30 \%$ of patients at two year of follow-up. In addition, up to $61 \%$ of cases with

\section{AKI would need dialysis at presentation $[1,12]$.}

Proteinuria and eosinophiluria are rarely observed. Hematuria, pyuria and granule-hyaline cylinders may be frequently observed in urine sediment; eosinophilia and hypocomplementemia, when present are suggestive of current illness or active disease [1].

Other organs may be affected, as well. High concentrations of hepatic enzymes suggest liver disease, as raised serum lipase and amylase suggest pancreatic disease $[1,12]$.

Imaging of the aorta by trans-esophageal ultrasound (TEE), MRI angiography or CT scan probably identify the source from where the embolization begun. TEE is the most commonly used method for detection and measurement of atherosclerosis in the aorta. It has been reported that a thickness $\geq 4 \mathrm{~mm}$ in the aortic arch is a novel predictor of developing cerebral embolism $[8,9]$.

Accurate diagnosis is made by renal biopsy. But, it may be histologically difficult to find cholesterol emboli due to patchy involvement [1,12]. Nevertheless, this procedure is not always possible to perform due to patient's clinical status. If the patient has skin manifestations, skin biopsy is preferable, because, in up-to $90 \%$ of biopsies, biconvex cholesterol crystal clefts occluding emboli are evidenced, besides, elongated needle-shaped clefts in small arteries, produced by cholesterol crystals and often accompanied by inflammatory infiltrates [1].

Differential diagnosis should include radicontrast acute tubular necrosis, systemic or renal vasculitis, immunoallergic interstitial nephritis and renal artery thrombosis $[1,12]$.

Actually there is no specific treatment for CES. Supportive care is the main target. All patients should receive secondary prevention of atherosclerotic disease. Treatment is based on statins, blood pressure control, stop smoking and glycaemic control in diabetics. Amputation or excision of necrotic areas may be necessary $[1,12,13]$.

Despite lack of evidence of antiplatelet agents, there is advisable to administer this treatment as prevention of other cardiovascular events in patients with atherosclerosis. Cessation of warfarin is suggested when CES is suspected, except in patients with atrial fibrillation or the one who carries a mechanical prosthetic valve [12]. The use of corticosteroid treatment is also controversial [1].

Belenfant et al. [14] demonstrate a favorable prognosis with a 1 -year mortality rate of $13 \%$, using an aggressive treatment protocol controlling the main risk factors, avoiding the use of anticoagulants and invasive procedures, blood pressure control, dialytic therapy and monitoring of nutritional state.

During the admission, confusional state and irritability disappeared after 72 hours. Rapid decline in renal function was meaningful. Creatinine increased to $8 \mathrm{mg} / \mathrm{dl}$, BUN $250 \mathrm{mg} / \mathrm{dl}$ and decreased urine output with water overload led us consider initiating hemodialysis. Because of the recent history of cardiac revascularization, lacunar stroke, impaired renal function and purpuric skin lesions, systemic cholesterol embolism was suspected. A skin biopsy of the mottled lesions on the left foot was performed. It showed skin with deep artery obstructed by a fibrin-crystalloid structure (needle leaf and optical empty) supporting cholesterol embolism diagnosis. Since the onset of clinical suspicion, we started treatment with aspirin and atorvastatin $40 \mathrm{mg}$ daily. Hemodialysis, 4 hours sessions, three times per week were performed for three months. After these three months, the patient recovered renal function. Residual renal function was maintained 
along time. Now day, His creatinine is $2.0 \mathrm{mg} / \mathrm{dl}$ and a GFR of $30 \mathrm{mil} /$ $\min / 1.73 \mathrm{~m}^{2}$.

\section{References}

1. Scolari F, Ravani P (2010) Atheroembolic renal disease. Lancet 375: 1650-1660. [Crossref]

2. Modi KS, Rao VK (2001) Atheroembolic renal disease. J Am Soc Nephrol 12: 17811787.[Crossref]

3. Meyrier A (2006) Cholesterolcrystal embolism: diagnosis and treatment. KidneyInt69: 1308-1312.[Crossref]

4. Fazio GP, Redberg RF, Winslow T, Schiller NB (1993) Transes ophagealecho cardiographically detected at heroscleroticaortic plaque is a marker for coronaryarterydisease. J Am Coll Cardiol 21: 144-150.[Crossref]

5. Tunick PA, Kronzon I (2000) Atheromas of thethoracic aorta: clinical and therapeutic update. J Am Coll Cardiol 35: 545-554.[Crossref]

6. Amarenco P, Duyckaerts C, Tzourio C, Hénin D, Bousser MG, et al. (1992) Theprevalence of ulcerated plaques in theaorticarch in patients with stroke. $N$ Engl $J$ Med 326: 221-225.[Crossref]

7. (1996) Atheroscleroticdisease of theaorticarch as a risk factor for recurrentischemicstroke. The French Study of Aortic Plaques in StrokeGroup. $N$ Engl $J$ Med 334: 1216-1221. [Crossref]
8. Katz ES, Tunick PA, Rusinek H, Ribakove G, Spencer FC, et al. (1992) Protrudingaorticatheromaspredictstroke in elderly patientsundergoingcardiopulmonary bypass: experience with intraoperativetransesophagealechocardiography. $J \mathrm{Am}$ CollCardiol 20: 70-77.[Crossref]

9. Tunick PA, Rosenzweig BP, Katz ES, Freedberg RS, Perez JL, et al. (1994) High risk for vascular events in patients with protrudingaorticatheromas: a prospectivestudy. $J$ Am CollCardiol 23: 1085-1090.[Crossref]

10. Amarenco P, Cohen A, Tzourio C, Bertrand B, Hommel M, et al. (1994) Atheroscleroticdisease of theaorticarch and the risk of ischemicstroke. $N$ Engl J Med 331: 1474-1479.[Crossref]

11. Mulay SR, Evan A, Anders HJ (2014) Molecular mechanisms of crystalrelatedkidneyinflammation and injury. Implications for cholesterol embolism, crystallinenephropathies and kidneystonedisease. Nephrol Dial Transplant 29: 507-14. [Crossref]

12. Kronzon I, Saric M (2010) Cholesterolembolizationsyndrome. Circulation 122: 631641.[Crossref]

13. Tunick PA, Nayar AC, Goodkin GM, Mirchandani S, Francescone S, et al. (2002) Effect of treatmentontheincidence of stroke and otheremboli in 519 patients with severe thoracicaortic plaque. Am J Cardiol 90: 1320-1325.[Crossref]

14. Belenfant X, Meyrier A, Jacquot C (1999) Supportivetreatmentimprovessurvival in multivisceralcholesterolcrystal embolism. Am J Kidney Dis 33: 840-850.[Crossref]

Copyright: (C2016 Hurtarte Sandoval AR. This is an open-access article distributed under the terms of the Creative Commons Attribution License, which permits unrestricted use, distribution, and reproduction in any medium, provided the original author and source are credited. 